\title{
Interventional Management of Intracranial Stenosis
}

\author{
Marc A. Lazzaro and Michael Chen ${ }^{*}$
}

Department of Neurological Sciences, Rush University Medical Center, Chicago, IL 60612, USA

\begin{abstract}
Worldwide, intracranial atherosclerosis is the most common cause of ischemic stroke and is associated with a high risk of recurrence. Endovascular therapies including angioplasty and stent implantation may help in secondary stroke prevention due to intracranial stenosis, however rigorous appraisal of clinical efficacy is currently lacking. This review aims to introduce the basic concepts involved with endovascular treatment of intracranial stenosis, its strengths and limitations, and discuss the available data. The importance of patient selection, procedural risks, patient outcomes, and surveillance goals are also highlighted.
\end{abstract}

Keywords: Intracranial stenosis, stent, neurointerventional, angioplasty, intracranial atherosclerosis, angiography, secondary stroke prevention.

\section{BACKGROUND}

As more stroke patients undergo cerebral vascular imaging, intracranial atherosclerosis is becoming increasingly identified as a putative mechanism for ischemic stroke. Although found in approximately $10 \%$ of stroke patients in the US [1], it is even more common in Asia, accounting for $30-50 \%$ of strokes, making it the most common cause of stroke worldwide [2]. In the US, this translates to more than 70,000 strokes per year related to intracranial atherosclerosis. Our understanding of the pathophysiology and treatment options remains underdeveloped in this challenging disease. The recurrent risk of stroke remains staggeringly high despite standard medical therapy [3]. Furthermore, those with symptomatic intracranial stenosis $\geq 70 \%$ face a recurrent stroke risk of $23 \%$ in the first year [4]. While improving flow would appear to diminish this stroke risk, surgical bypass techniques have remained controversial and unproven [5]. Recent enthusiasm has emerged for endovascular treatment options that hold the promise for immediate and minimally invasive revascularization of stenotic intracranial vessels to improve flow and potentially reduce future stroke risk.

\section{CURRENT ENDOVASCULAR APPROACHES}

The goal of endovascular revascularization is to restore luminal patency with minimal vessel wall injury, reasonable safety, improved outcomes, and adequate durability. Initially developed in the coronary and peripheral vasculature, endovascular approaches have undergone modification to accommodate the tortuous and delicate intracranial anatomy. As catheter and guidewire flexibility have improved, stents have evolved to include self-expanding and drug-eluting designs. Likewise, techniques have changed with modifications to balloon sizing and inflation. Endovascular therapy for intracranial arterial stenosis includes percutaneous transluminal angioplasty (PTA) with or without stent placement.

\footnotetext{
*Address correspondence to this author at the Department of Neurological Sciences, Rush University Medical Center, Chicago, IL 60612, USA; Tel: 312-942-4500; Fax: 312-563-2206; E-mail: michael_chen@rush.edu
}

\section{PERCUTANEOUS TRANSLUMINAL ANGIOPLASTY}

\section{Angioplasty Mechanism and Device Design}

Balloon catheters include a catheter tube and a distensible balloon at the distal end that is inflated with a mixture of contrast and saline solution to a desired diameter and subsequently deflated by withdrawal of the fluid. Balloons are noncompliant, being self-limited in size distending only to a specific diameter or volume, and are inflated to about 6 to 8 atmospheres of pressure. They may be used to restore vessel patency or expand stents for intraarterial placement. The mechanism of angioplasty was initially thought to result from compression of atheromatous material; however, this has been shown to account for little improvement of lumen diameter. With a small amount of wall stress, arteries behave as truly elastic; however, further stretching of the vessel wall results in partial disruption of the intima and media resulting in a permanent arterial widening [6]. Axial redistribution of plaque material may also contribute to luminal diameter increase.

\section{Evolution of Intracranial Angioplasty}

Intracranial percutaneous transluminal angioplasty (PTA) was first described in 1980 with treatment of a basilar artery stenosis in two patients [7]. Successful intracranial angioplasty of a symptomatic, stenotic cavernous carotid artery was reported in 1984 [8], and additional case reports followed [9, 10]. Enthusiasm about treating intracranial atherosclerosis was tempered by a variety of complications including arterial dissection, vasospasm, perforator vessel compromise, and distal embolization [11]. Intraprocedural dissection rates, although largely asymptomatic, were reported in $40 \%$ to $50 \%$ of PTA cases $[12,13]$. A series of 25 patients with 25 vertebral or basilar artery stenoses showed $40 \%$ reduction in stenosis by PTA; however, the procedures carried an overall $28 \%$ risk of stroke or death, and risk of disabling stroke or death was $16 \%$ [14]. A safer approach to intracranial angioplasty was demonstrated with slow balloon inflation, over minutes versus seconds, combined with balloon undersizing to minimize intimal damage, thrombus formation, and acute vessel occlusion. 
The authors reported a dissection rate of $14 \%$ (7/50) with the newer technique [13]. This technique has been adopted and reported in subsequent series with similar complication rates $[15,16]$.

Limited data for long-term follow up of PTA are available. Smaller series have suggested an annual stroke rate of $1.8 \%$ to $3.2 \%$ [17], and intracranial re-stenosis of $8 \%$ to $27.4 \%$ during variable follow-up times within one year $[13,15]$. A recent large series included 120 patients with 124 lesions of greater than $50 \%$ stenosis treated by primary angioplasty. The authors described a peri-procedural stroke and death rate of $5.8 \%$ and an annual stroke rate of $3.2 \%$ [16]. This study represents the largest series to date on primary angioplasty alone and shows a remarkably low annual stroke rate after treatment. It must be cautioned that these data are limited by selection bias and retrospective analysis. A common limitation of the series and others studying follow-up of intracranial atherosclerosis is that the severity of concurrent atherosclerotic vascular disease

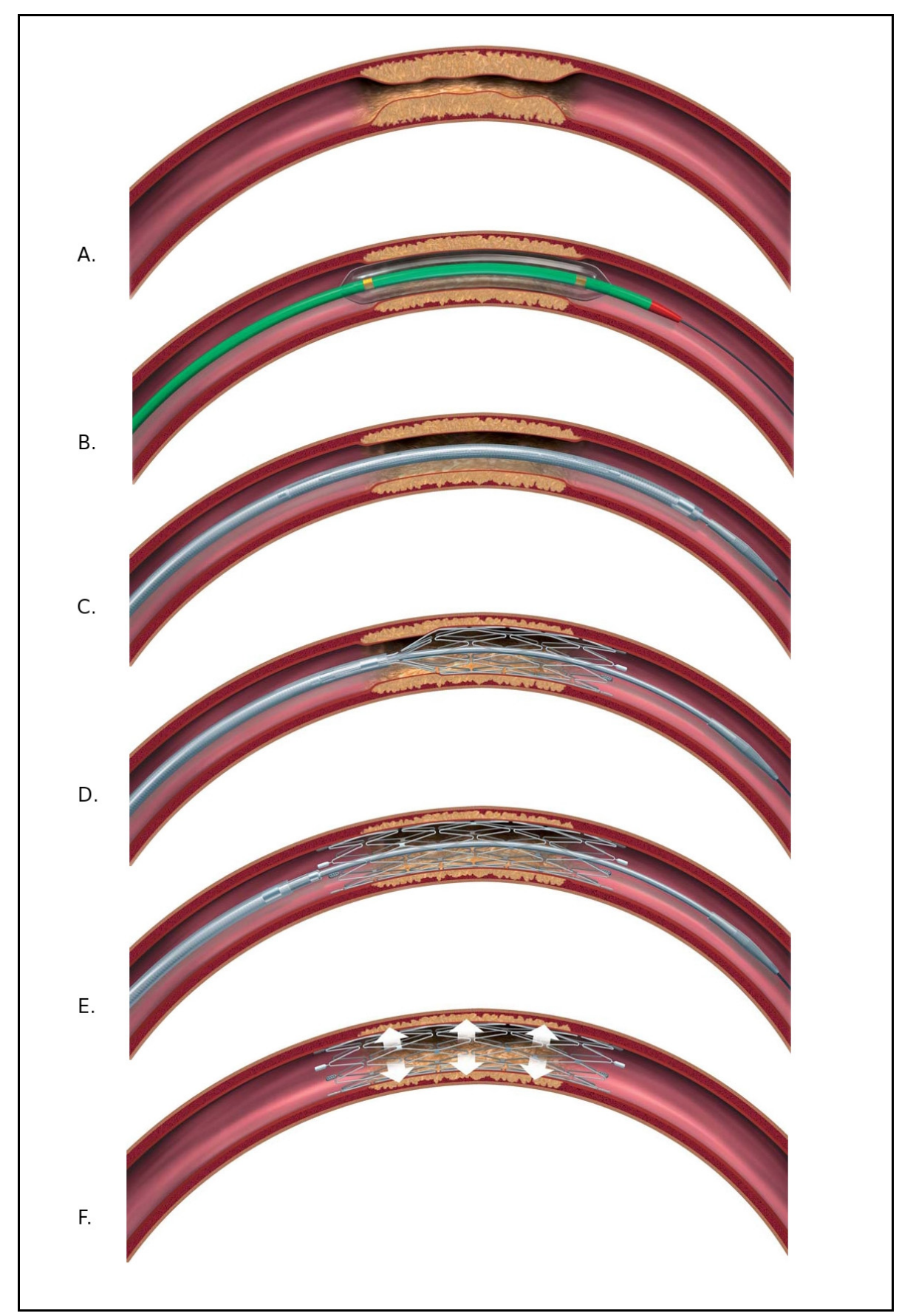

Fig. (1). Depiction of intracranial stent implantation using the Wingspan stent system. Severe focal narrowing due to atherosclerosis is depicted (A). First, a Gateway balloon catheter is advanced over a guidewire to cross the lesion and slowly inflated to perform submaximal angioplasty (B). After removal of the balloon catheter, the stent delivery catheter is advanced and positioned symmetrically across the dilated lesion $(\mathbf{C})$. The stent delivery catheter is withdrawn, unsheathing the self-expanding stent $(\mathbf{D}, \mathbf{E})$. The implanted stent $(\mathbf{F})$ spans the entire lesion and exerts an outward radial force (arrows). Adapted image courtesy of Boston Scientific, Inc. All rights reserved. 
elsewhere in the body likely also contributes to future stroke risk, independent of a specific cerebral vascular stenosis. Therefore, extrapolation of these future stroke rates to clinical scenarios must also include an evaluation to see if baseline demographics are also similar. Nevertheless, the major limitations of angioplasty alone include the risk of vessel dissection, and the high rate of restenosis and questionable long-term durability.

\section{INTRACRANIAL STENTS}

\section{Stent Mechanism and Device Design}

Intracranial stents range in diameter from about $2.5 \mathrm{~mm}$ to $5 \mathrm{~mm}$ and are intended to maintain vessel lumen patency after angioplasty. The goal in stent design is to achieve biocompatibility, corrosion resistance, flexibility, minimal thrombogenicity, and adequate fluoroscopic visualization in a device can be technically implanted safely and consistently. Older stent materials included stainless steel and cobalt-based alloys, which have been limited in performance by restricted elastic deformation properties [18]. Current materials include nitinol, which is an equiatomic mixture of nickel and titanium with properties of super-elasticity and shape memory characteristics that make it favorable for use in intracranial revascularization. The super-elasticity allows the nitinol stent to be constrained in a low profile catheter with the flexibility to accommodate navigation through tortuous anatomy. Upon deployment, the stent self-expands to its original size and shape (Fig. 1). After expanding to the size of the vessel, it exerts a low continuous outward radial force (less than $0.1 \mathrm{~atm}$ for the Wingspan stent) that is thought to assist with maintaining long-term lumen patency [19]. Fluoroscopic visibility decreases due to the small stent profile, which requires electroplating of radiopaque markers on the distal and proximal borders (Fig. 2) [18].

Self-expanding stents do not necessitate delivery over balloons, therefore they can be delivered within microcatheters alone, improving navigation within small intracranial arteries. Stent geometry varies widely, however common intracranial stent designs have included closed-cell and open-cell sequential ring construction. In open-cell construction, some or all of the internal inflection points of the structural members are not connected by bridging elements allowing for improved longitudinal flexibility [20]. Flexibility is important for the ability of the stent to conform to curved and tapered vessels of the cerebrovasculature.

Newer technology includes drug-eluting stents (DES) which offer local delivery of a pharmacologic agent to the vessel wall to suppress neointimal proliferation. The desired drug is adherent to the stent by a polymer coating that allows sustained release. DES have been widely adopted in interventional cardiology leading to significant reductions in restenosis rates. Two DES are currently available in the US for use in coronary vessels, a sirolimus-eluting stent (Cypher, Cordis Corp., FL) and a paclitaxel-eluting stent (Taxus, Boston Scientific, MA).

\section{Evolution of Intracranial Stent Placement}

While balloon-mounted coronary stents were initially used with variable results [21-23], the development of stents designed for the cerebrovasculature has yielded promising results. Two stents, the Neurolink (Guidant Corporation) and Wingspan (Boston Scientific, Natick, MA) stents, have received a Humanitarian Device Exemption from the United States Food and Drug Administration and are currently used in endovascular treatment of intracranial stenosis. The Neurolink stent was designed with fewer links to improve negotiation within tortuous intracranial vessels and reduce the likelihood of vessel wall injury [24]. This stent was evaluated for safety and feasibility in the Stenting of Symptomatic Atherosclerotic Lesions in the Vertebral or Intracranial Arteries (SSYLVIA) study [24]. Of the 61 patients enrolled, $70.5 \%$ had intracranial atherosclerosis. Strokes occurred in $6.6 \%$ of treated patients within 30 days and another $7.3 \%$ between day 30 and 1 year. Overall, restenosis occurred in $35 \%$ of patients and $39 \%$ of these were symptomatic.

The Wingspan system is a nitinol self-expanding stent [25]. The target lesion is pre-dilated with slow-inflation of an undersized noncompliant balloon followed by deployment of the self-expanding Wingspan stent using an exchange wire platform. This technique is intended to minimize trauma to the parent vessel, thereby reducing the likelihood of immediate endothelial injury. The continuous outward radial force is designed to provide further lumen expansion and which may obviate the need for aggressive balloon angioplasty. Of the 45 patients enrolled in the Wingspan study, stenosis was reduced from an average baseline of $74.9 \%$ to $31.9 \%$ after stent implantation, and 30-day ipsilateral stroke/death rate was $4.5 \%$, which rose to $7.0 \%$ at the 6-month follow up. The Wingspan stent system was evaluated in a larger US Multicenter study including 78 patients with 82 treated lesions and showed a $6.1 \%$ major periprocedural complication rate at 30 days [26]. Outcome data from the use of the Wingspan stent in a more select, high risk group (70 to $99 \%$ intracranial stenosis), was reported on a total of 129 patients [27]. The frequency of any stroke, intracerebral hemorrhage, or death within 30 days or ipsilateral stroke beyond 30 days was $14 \%$ at 6 months and $25 \%$ had $\geq 50 \%$ restenosis on follow-up angiography. Longer-term outcome data on the Wingspan system was only recently reported from a single center where 51 patients had an overall $10 \%$ rate of stroke or death at a mean follow up time of up to 14.6 months [28].

Angioplasty and implantation of intracranial stents has been demonstrated to be technically possible with success rates of $\geq 95 \%$ in most reports, while reduction of residual luminal stenosis to below $50 \%$ is commonly reported [2533]. However, these are largely self-reported results. Stent success has been defined as adequate device performance based on an investigator rating system and a reduction in the degree of stenosis to $<50 \%$ immediately after implantation [25].

Due to considerable stent re-stenosis rates with nitinol stents, interest has developed for the possible benefit of drug-eluting stents (DES) in maintaining long-term vessel patency. Drug-eluting stents target cellular proliferation by local delivery of drug while minimizing systemic toxicity. Sirolimus-eluting stents in coronary arteries have been shown to significantly reduce restenosis [34]. The use of DES for intracranial stenosis has not been well-studied. Small series of patients receiving either sirolimus or 
paclitaxel-coated stents have reported a 0 to $14 \%$ restenosis rate at variable follow-up times over one year and major stroke or death rate of up to $11 \%$ [35-37]. The largest series using drug-eluting stents included 62 lesions (59 patients) which were both intracranial (26) and extracranial (36) [33]. Fifty vessels were evaluated with angiography at a median 4month follow-up period and showed greater than 50\% stenosis in $7 \%$ of the extracranial stents and $5 \%$ of the intracranial stents. Post-implantation dual antiplatelet therapy varied from 3-6 months duration. Although early restenosis rates seem improved, the long-term durability of coronary artery DES is uncertain. Reports of late thrombosis have suggested a possible hypersensitivity reaction to a stent polymer [38], and late endothelialization [39]. Furthermore, the risk of neural toxicity from DES has been a target of inquiry. Data from the use of sirolimus-eluting stents used in canine cerebral arteries shows no toxicity [40]. Another major concern with DES for intracranial circulation will be navigating a rigid stent into the brain and technical success of stent delivery and placement for a wide variety of lesions and locations.

\section{ANGIOPLASTY ALONE VERSUS ANGIOPLASTY WITH STENTING}

Superiority of either angioplasty alone or angioplasty with stenting has not been clearly demonstrated. PTA was compared with stent placement in 24 patients with petrous or cavernous internal carotid artery stenosis and revealed greater immediate decrease in stenosis ratio in those treated with stent placement compared to those with only PTA (stenosis decrease by $73.4 \%$ versus $42.5 \%$, respectively) [12]. Additionally, there was greater than $50 \%$ re-stenosis in four patients who underwent PTA and no re-stenosis in those who received stent placement. A non-randomized comparison of angioplasty versus drug-eluting stent placement showed no significant difference between major stroke or death between the two cohorts at 12 month evaluation [41]. A report on treatment of 69 lesions over a 7year period with angioplasty alone or with stent implantation $(76.8 \%, 53 / 69)$ showed an overall restenosis rate of $15.9 \%$ (with $18.2 \%$ being symptomatic [2/11]). The restenosis rate was $50 \%(8 / 16)$ for angioplasty and $7.5 \%(4 / 53)$ for stenting [32]. These data suggest durability of luminal dilation may be enhanced by stent placement.

\section{SAFETY OF ENDOVASCULAR THERAPY}

\section{Concerns and Risks}

Endovascular procedures involve intracranial manipulation of guide wires and catheters as well as balloon inflation and stent implantation, each of which carries the risk of vessel injury or embolic events. The intracranial arteries have a thin adventitial layer and are surrounded only by the cerebrospinal fluid filled subarachnoid space. Injury with balloon dilation or catheter and guide-wire manipulation may result in perforation, dissection, and lifethreatening subarachnoid hemorrhage. The risk of adverse cerebral hemorrhagic events is exacerbated by the concurrent use of dual antiplatelets if stent placement is anticipated. Operator and institution experience may influence outcomes as has been suggested by the increased risk of adverse events in patients treated at low volume sites [42]. Development in device technology, and improved technique will likely reduce these complications, however peri-procedure complication rates remain an important consideration. Plaque manipulation in cerebral vessels carries the unique risk of perforator vessel occlusion, particularly in the first segment of the middle cerebral artery or the basilar artery, which may lead to infarcts of cerebral tissue that have little inherent collateral reserve. The risks of endovascular therapy extend beyond those inherent to the catheter procedure and include risk of general anesthesia. General anesthesia is frequently used for intracranial stent implantation and therefore may limit stent therapy to those patients without significant co-morbid conditions [43].

\section{Procedure Complications}

Rates of complications from endovascular procedures vary widely from $4.5 \%$ to $50 \%$ among reports of varying interventional modalities including PTA, balloon-mounted stents, and self-expanding stents [12, 13, 16, 24-27, 44]. These peri-procedure complications are commonly reported as adverse events within the first 30 days post-procedure. The types of reported complications vary and frequently include ischemic stroke, dissection, intracranial hemorrhage, and death. A retrospective review to evaluate procedurerelated cerebrovascular complications reported on 169 patients (181 lesions) who underwent stent placement for intracranial stenosis $>50 \%$ found a $11.8 \%$ complication rate at 30 days which included intracranial hemorrhage, targetlesion thrombosis, perforator stroke, embolic stroke, TIA, and vessel dissection [45]. Perforator stroke has been reported in higher frequency after stenting stenoses that have adjacent preoperative perforator infarct [46]. A Cochrane database review in March of 2006 identified 79 reports that included 1999 cases comparing best medical care plus angioplasty with or without stent placement, with best medical care alone [47]. The overall perioperative rate of stroke was $7.9 \%$ (95\% confidence intervals (CI) $5.5 \%$ to $10.4 \%$ ), perioperative rate of death was $3.4 \%$ (95\% CI $2.0 \%$ to $4.8 \%$ ), and perioperative rate of stroke or death was $9.5 \%$ (95\% CI $7.0 \%$ to $12.0 \%)$.

\section{Event Rate}

Rates of ischemic stroke or death also vary widely among reports, ranging from $3.2 \%$ to $10 \%[16,24,25,28,48]$. Interpretation of these rates is further complicated by the inconsistent mean follow-up times that range from 6 to 14 months. An interesting comparison has been made regarding complication and event rates between balloon-mounted and self-expanding stents. The higher rate of periprocedural complication with balloon-mounted stents $(7-10 \%)$ with a lower rate of long-term recurrent events at follow-up (2.9$3.7 \%)$ when compared to self-expanding stents $(6.4 \%$ periprocedural complication and $10.3 \%$ long-term event rates) may suggest an increased risk of periprocedural events in balloon-mounted stents but decreased delayed events compared to self-expanding stents [49].

\section{In-Stent Restenosis}

An important limitation to the long-term success of endovascular therapy for intracranial stenosis is restenosis. Following angioplasty, elastic recoil accounts for acute lumen restenosis, which is followed by negative remodeling and neointimal hyperplasia over the ensuing six months [50]. 
Balloon injury to the vessel results in a cascade of events including an inflammatory response that largely involves leukocyte migration, and results in neointimal formation [51]. Stent implantation reduces the element of elastic recoil and negative remodeling; however current stent technology is overcome by the potent inflammatory response to the stent and proliferative events that lead to neointimal hyperplasia. In-stent restenosis may be decreased with antiplatelet therapy and use of drug-eluting stents, while angioplasty may be used for re-dilation of a stenosed vessel. Identifying those patients who will be at risk for re-stenosis is challenging; however, factors associated with restenosis include small vessel size $(<2.5 \mathrm{~mm})$, interventions performed in the setting of an acute stroke [32], location of stenosis at the supraclinoid segment, and older age [52]. The reported rate of restenosis has been high, up to $25 \%$ for the Wingspan stent at 6 months, though the majority of cases have been asymptomatic [32]. Although a 1-year rate of restenosis was reported to be $15.9 \%(11 / 69)$, only $18.2 \%$ of those $(2 / 11)$ were symptomatic [32]. This series included both angioplasty alone and with stenting and some of the stents used were drug-eluting. The reported restenosis rates are also likely subject to compliance with post-procedure antiplatelet regimens and whether drug-eluting stents have been used, methods which vary widely among reported cases.

\section{MANAGEMENT}

\section{Patient Selection}

Besides identifying patient characteristics of those at highest risk of recurrent stroke (see Chapter 3), the lesion characteristics likely influence the technical success of endovascular therapy. In addition to degree of stenosis $(\geq$ $70 \%$ ), location of the target lesion in relation to perforator vessels and branches is a consideration as is technical accessibility of the lesion in predicting the success of effective angioplasty and stent placement. Morphology of the lesion is also related to risk of complications and restenosis [31]. Because of these associations, a classification of lesions based on location, morphology, and access was proposed (LMA classification) suggesting importance of individual lesion characteristics in deciding therapy [31]. Integration of a classification system such as this may assist in identifying those patients who would benefit most from endovascular therapy. Prospective data suggests there is not a greater risk of stroke in either an anterior or posterior circulation stenosis [4]. However, periprocedural complications have been higher in the posterior circulation compared to anterior circulation [42, 53]. Therefore, greater caution may be appropriate in the decision to pursue a posterior circulation stenosis with endovascular therapy. Angiographic appearance of the stenotic lesion may offer additional information to facilitate patient selection. In a series of 42 hemodynamically significant intracranial lesions of greater than $70 \%$ stenosis treated with PTA, angiographic characteristics of the lesion including length, concentric or eccentric lesion, and tortuosity were assessed [54]. These data suggested that PTA for "simple" intracranial lesions in symptomatic patients produces a more favorable clinical outcome, while angulated lesions with tortuous access were associated with higher complications.
The appropriate timing for endovascular intervention is unknown [55]. A short duration of angina has been correlated with increased distensibility of atheroma in the coronary arteries, suggesting that the early stage of development of an intimal plaque involves largely atheromatous material, whereas subsequent fibrous proliferation and intimal calcification may limit effectiveness of intervention [56]. Time since the qualifying event was an independent predictor of risk for stroke recurrence in the WASID trial with the highest risk occurring if enrolled within 17 days after a symptomatic event [4]. Although chronic severe intra-arterial occlusion has been treated with angioplasty and stent placement [57], early revascularization has been emphasized given the predominant risk of recurrent stroke in the early post-event period. However, acute revascularization of intracranial vessels may confer higher periprocedural complications. A report of 18 neurologically unstable patients with 21 lesions who underwent urgent $(6$ patients had acute stroke within 3 days of procedure, 2 patients had 2 days of progressive neurologic deficit, and 10 patients had recurrent TIA) revascularization with angioplasty or stent-assisted angioplasty revealed major periprocedural complications in 50\% (9/18) [43]. The appropriate procedure timing may be within the sub-acute period following the qualifying event. Nevertheless, it appears that if able to be performed safely, the greatest benefit is derived within days of the initial event.

\section{Post-Treatment Management}

\section{Antiplatelet Therapy}

To reduce the risk of stent thrombosis, long-term management with antiplatelet therapy has been routinely used. In patients with acute coronary syndrome undergoing percutaneous coronary intervention, pretreatment with clopidogrel and aspirin was shown to be beneficial in reducing 30-day post-procedure major ischemic events [58]. The American Heart Association guidelines recommend dual antiplatelet therapy for 1 month for bare metal stents and up to 6 to 12 months for drug eluting stents [59]. Adjunctive antiplatelet therapy has also been employed in management of stent implantation for intracranial stenosis. In the SSYLVIA trial, pre-procedure aspirin and clopidogrel were used followed by 4 weeks of clopidogrel and one year of aspirin therapy for placement of a bare-metal stent [24]. A similar regimen was used in the Wingspan study with preprocedure aspirin and clopidogrel treatment, followed by daily clopidogrel for one month and aspirin thereafter for life [25]. Dual antiplatelet therapy for an extended period has become common practice following drug-eluting stent implantation due to a possible increased risk of delayed instent thrombosis. The practice of antiplatelet pre-medication for intracranial drug-eluting stent placement with 5-7 days of aspirin $(325 \mathrm{mg} / \mathrm{d})$ and clopidogrel $(75 \mathrm{mg} / \mathrm{d})$ followed by clopidogrel $(75 \mathrm{mg} / \mathrm{d})$ for 6 to 12 months and lifelong aspirin $(325 \mathrm{mg} / \mathrm{d})$ is commonly used $[35,37,60]$.

Antiplatelet resistance is a recently recognized challenge in the management of patients who undergo cerebrovascular stent placement. Clopidogrel resistance occurred in about half of patients undergoing cerebrovascular stent placement in one study [61]. Additionally, the authors reported that older patients and those with diabetes mellitus may be poor 
responders to clopidogrel. A similar study found that $21 \%$ of patients premedicated with aspirin and clopidogrel were nonresponders to aspirin [60]. Furthermore, a greater percentage of inadequate platelet inhibition was noted in patients premedicated with clopidogrel when compared to aspirin ( $66 \%$ versus $13 \%)$ and same-day antiplatelet loading may be insufficient [62].

An additional challenge in antiplatelet therapy is compliance. Perioperative non-compliance with antiplatelet therapy was found to be significantly associated with targetlesion thrombosis [45]. Given the consequences of restenosis, the ideal antiplatelet agent, dosing, duration of therapy, responsiveness to treatment, and compliance are as critical an aspect to prevent further ischemic events as the technical success of the stent implantation.

\section{Surveillance Imaging}

Catheter angiography remains the ideal modality for surveillance imaging (Fig. 3). Following a standardized method of measurement with angiography, the degree of intracranial stenosis can be reliably evaluated [63]. Although neurologic complications of catheter angiography are rare $(0.34 \%)$ [64], non-invasive evaluation would further minimize risk. The conventional computerized tomography (CT) imaging algorithm fails when reconstructing an image of an interface between an unusually dense structure (a stent) and surrounding soft tissue, resulting in beam-hardening artifact. CT angiography of endovascular stents is subject to an exaggerated thickening or blooming of the stent struts causing artificial lumen narrowing [65]. In general, CT angiography overestimates the degree of in-stent stenosis [66]. These factors limit the usefulness of CT angiography in surveillance imaging. A recent report of rotational acquisition of a c-arm mounted flat-panel detector CT has shown promise as a non-invasive method for follow-up [67].

Magnetic resonance angiography (MRA) is an alternative non-invasive method of imaging intracranial stents, although similar challenges with image artifact exist. The paramagnetic nature of a metallic stent causes a localized distortion of the magnetic fields resulting in loss of signal and artifact. MR imaging at field strengths of up to 3 Tesla in patients with implanted nitinol stents has been previously demonstrated as safe [68]. Stainless-steel stents impart extensive signal loss at the level of the stented area, whereas nitinol stents are associated with less distortion allowing for improved MRA vessel imaging, which can be enhanced with contrast [69]. Quantitative MRA (QMRA) has been used in evaluation of an extracranial vertebral artery stent [70], and more recently as a screening tool for detecting intracranial in-stent stenosis [71]. The latter study reviewed 13 cases of stent-assisted coiling and 1 case of stent placement for atherosclerosis and found that time-of-flight MRA was nondiagnostic in detecting in-stent stenosis due to coil or stent artifact. However, a greater than $20 \%$ reduction in blood flow on QMRA was associated with the presence of greater than $50 \%$ in-stent stenosis. Quantitative MRA may have a role in screening for in-stent restenosis.

The optimal timing and modality for surveillance imaging following endovascular therapy for intracranial stenosis is unresolved. Additionally, long-term data on restenosis rates are not available. Follow-up with conventional angiography at three months has been proposed [72].

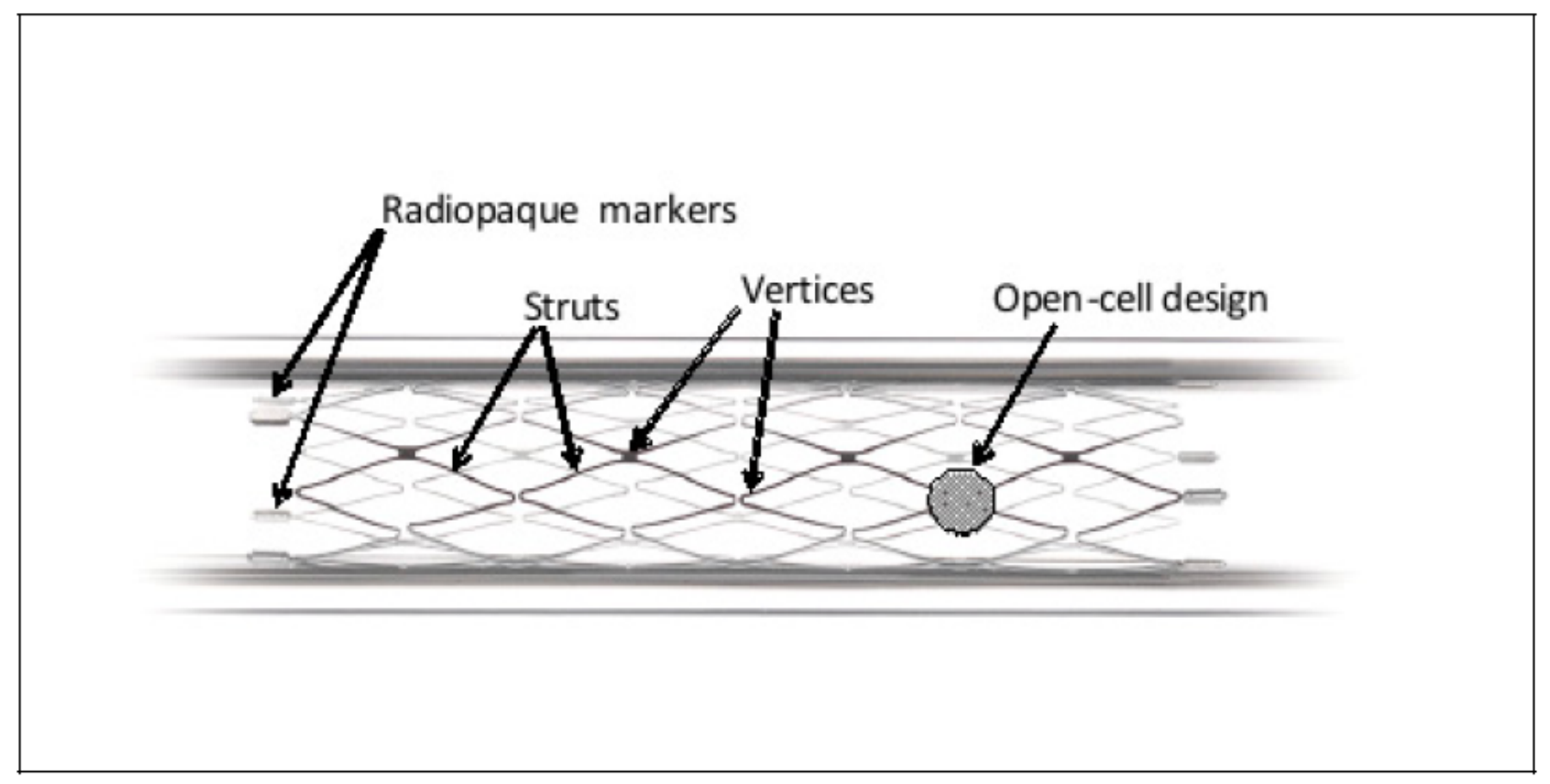

Fig. (2) Depiction of the Wingspan stent in an artery showing various components. Radiopaque markers placed on the ends of the stent allow for visualization during and after stent implantation. Struts form the stent framework and are either joined or open at each vertex. Depicted in this image is an open-cell design which offers greater flexibility than a closed-cell design. Adapted image courtesy of Boston Scientific, Inc. All rights reserved. 


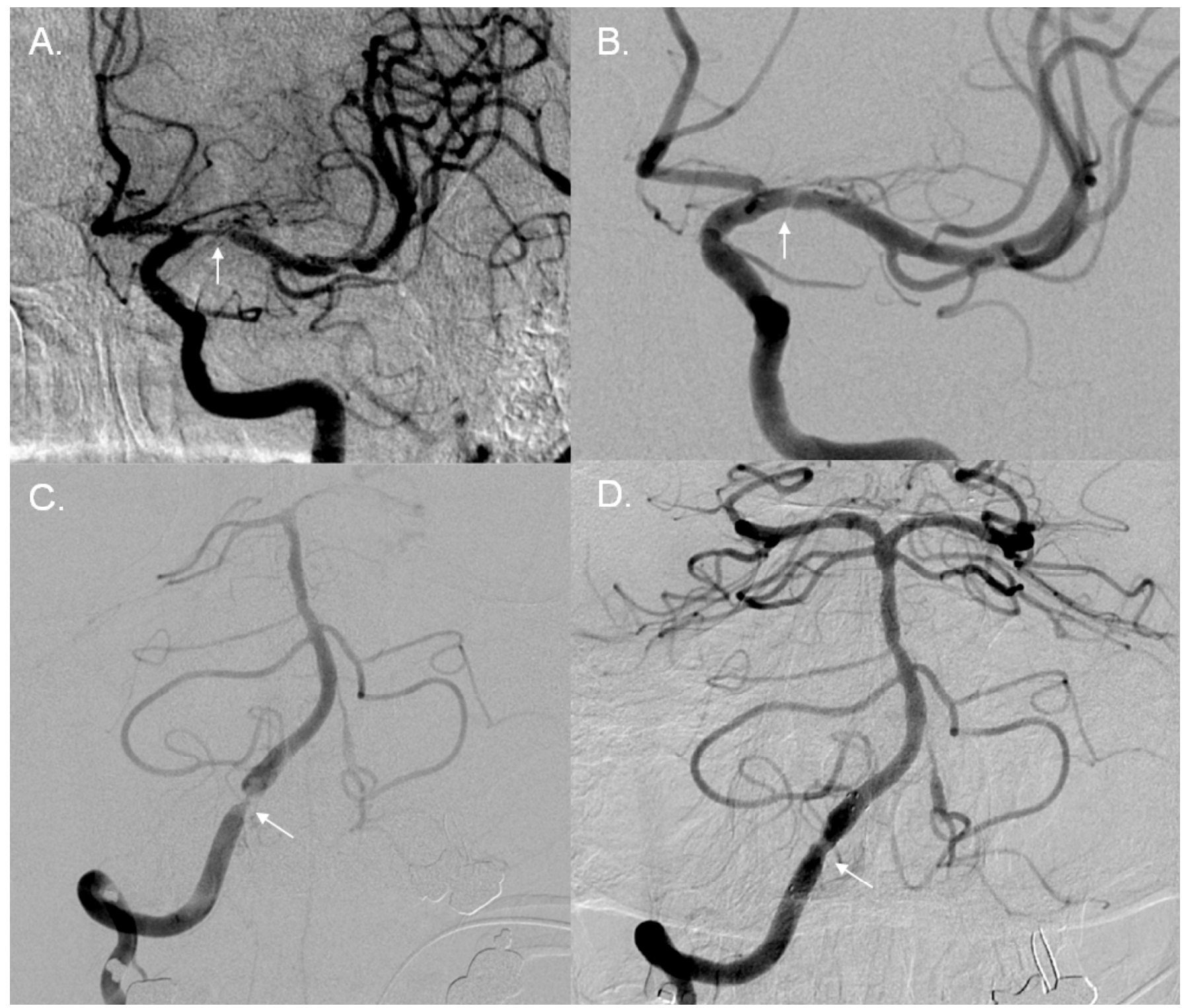

Fig. (3). Anteroposterior digital subtraction angiogram demonstrating 70\% stenosis (arrow) of the left proximal middle cerebral artery (A), and postangioplasty and stent implantantation study demonstrating recanalization (arrow) after stent placement (B). Anteroposterior digital subtraction angiogram demonstrating $90 \%$ stenosis (arrow) of the right vertebral artery (C), and postangioplasty and stent implantation study demonstrating recanalization (arrow) after stent placement in the right vertebral artery (D).

\section{SUMMARY}

Whether endovascular therapy can improve the natural history risk of hemodynamically significant intracranial stenosis remains unknown. The management of intracranial stenosis is challenging and optimal therapy is unclear at this time. Data from the WASID trial showed that with best medical therapy, there was an $11 \%$ to $14 \%$ chance of recurrent stroke in the first and second years following the initial event. Furthermore, those with stenosis of $\geq 70 \%$ had up to $23 \%$ risk of recurrent stroke at one year. The high rate of stroke recurrence among those with high grade intracranial atherosclerotic stenosis presents an appropriate opportunity for the investigation of endovascular therapies to reduce this risk.

Interpretation of data from reports of endovascular therapy for intracranial stenosis is challenging with widely heterogeneous groups represented by varying degrees of stenosis, type of treatment (angioplasty alone, angioplasty with stent), type of stent (balloon-mounted, self-expanding, drug-eluting), lesion location, follow-up duration, and postprocedure antiplatelet therapy (Table 1). This is compounded by an overall lack of randomized controlled trial data, which is of particular importance because of the wide spectrum of atherosclerotic disease severity. The available data suggest that endovascular therapy carries a peri-procedural risk of about $5-10 \%$ at 30 days and a $5 \%$ stroke or death risk in the first year after 30 days. These cumulative risks approach the recurrent stroke risk observed in patients treated with medical therapy alone. Therefore, it seems reasonable that with further experience, improved technique, and advances in device technology, endovascular therapy may have a substantial role in treating this challenging disease. 
Table 1. Major Studies of Intracranial Stenosis Treatment

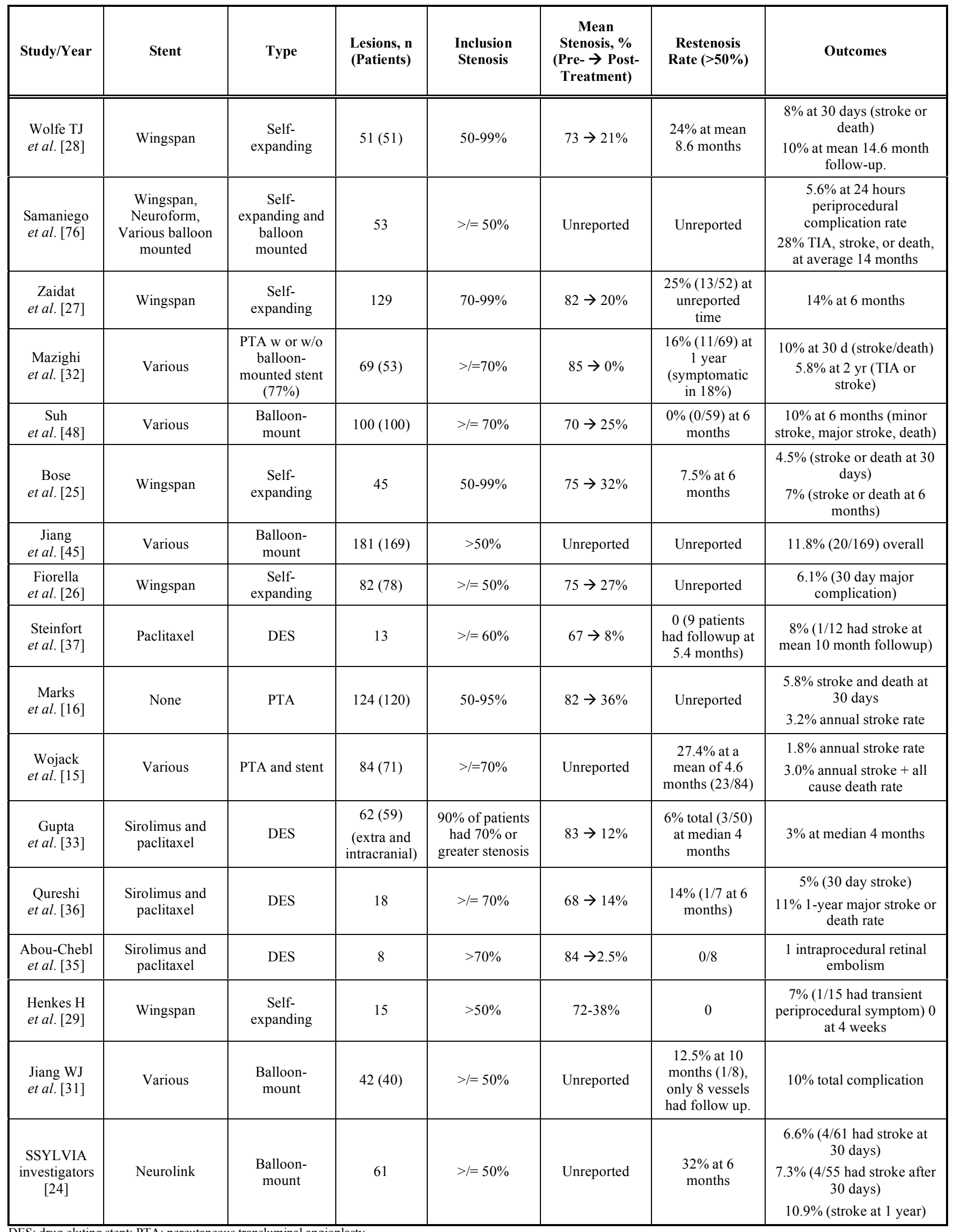


Some authors caution that a judgment on the effectiveness of intracranial endovascular angioplasty and stenting therapy may be premature when the field is only in its infancy, and that further device development, technique, and experience are needed to truly understand its safety and efficacy [73]. The evolving variables in endovascular treatment of intracranial stenosis include technique, the growing technology of balloons and stents, post-procedure antiplatelet management, and surveillance imaging.

Rigorous scientific evaluation of endovascular therapy remains to be completed. The ongoing phase III clinical trial, Stenting and Aggressive Medical Management for Preventing Stroke in Intracranial Stenosis (SAMMPRIS), will compare maximum medical therapy alone with maximum medical therapy and adjunctive intracranial angioplasty and stenting in patients with symptomatic intracranial stenosis greater than or equal to $70 \%$ [74].

\section{CONCLUSIONS}

The current data suggest that endovascular therapy has promise in the treatment of intracranial stenosis $\geq 70 \%$ in patients who remain symptomatic despite medical therapy. A recent publication of the American Heart Association guidelines on neurointerventional procedures has advised that endovascular therapy may be considered for patients with symptomatic severe intracranial stenosis $(\geq 70 \%$ luminal narrowing) despite optimal medical therapy [75]. This practice is becoming widely adopted with the increasing skill of interventionalists and advancing device technology in the setting of a complex and challenging disease that carries a strikingly high risk of future stroke. The use of endovascular therapy for intracranial stenosis however currently lacks rigorous appraisal of its ability in conferring additional benefit over and above optimal medical therapy alone. The ongoing SAMMPRIS trial aims to provide this data; however, clinical application of these results will be challenging with the rapidly changing field of neuroendovascular therapy. Significant advances have been made in the arena of neuroendovascular therapy over the past two decades and accelerated growth is anticipated. Device technology is quickly developing, endovascular technique will continue to progress, and the experience of interventionalists with the use of these tools will increase. Aggressive medical treatment of risk factors such as hypertension, diabetes, and hypercholesterolemia is fundamental in prevention of stroke from intracranial artery narrowing. Improved patient selection with better understanding of risk factors and predictors of outcomes will allow us to better select patients who will truly benefit from interventional approaches to intracranial atherosclerosis.

\section{ABBREVIATIONS}

$$
\begin{array}{ll}
\text { PTA } & =\text { Percutaneous transluminal angioplasty } \\
\text { DES } & =\text { Drug-eluting stent } \\
\text { WASID } & =\text { Warfarin-Aspirin Symptomatic Intracranial } \\
& \text { Disease Study } \\
\text { CT } & =\text { Computerized tomography } \\
\text { MRI } & =\text { Magnetic resonance imaging } \\
\text { rCBF } & =\text { Regional cerebral blood flow }
\end{array}
$$

MRA = Magnetic resonance angiography

QMRA = Quantitative magnetic resonance angiography

SSYLVIA = Stenting of Symptomatic Atherosclerotic Lesions in the Vertebral or Intracranial Arteries

SAMMPRIS $=$ Stenting and Aggressive Medical Management for Preventing Stroke in Intracranial Stenosis

\section{REFERENCES}

[1] Sacco RL, Kargman DE, Gu Q, Zamanillo MC. Race-ethnicity and determinants of intracranial atherosclerotic cerebral infarction. The northern manhattan stroke study. Stroke 1995; 26: 14-20.

[2] Wong LK. Global burden of intracranial atherosclerosis. Int $\mathbf{J}$ Stroke 2006; 1: 158-9.

[3] Chimowitz MI, Lynn MJ, Howlett-Smith H, et al. Comparison of warfarin and aspirin for symptomatic intracranial arterial stenosis. N Engl J Med 2005; 352: 1305-16.

[4] Kasner SE, Chimowitz MI, Lynn MJ, et al. Predictors of ischemic stroke in the territory of a symptomatic intracranial arterial stenosis. Circulation 2006; 113: 555-63.

[5] Garrett MC, Komotar RJ, Starke RM, et al. The efficacy of direct extracranial-intracranial bypass in the treatment of symptomatic hemodynamic failure secondary to athero-occlusive disease: A systematic review. Clin Neurol Neurosurg 2009; 111: 319-26.

[6] Castaneda-Zuniga WR, Formanek A, Tadavarthy M, et al. The mechanism of balloon angioplasty. Radiology 1980; 135: 565-71.

[7] Sundt TM Jr, Smith HC, Campbell JK, Vlietstra RE, Cucchiara RF, Stanson AW. Transluminal angioplasty for basilar artery stenosis. Mayo Clin Proc 1980; 55: 673-80.

[8] O'Leary DH, Clouse ME. Percutaneous transluminal angioplasty of the cavernous carotid artery for recurrent ischemia. AJNR Am J Neuroradiol 1984; 5: 644-5.

[9] Purdy PD, Devous MD Sr, Unwin DH, Giller CA, Batjer HH. Angioplasty of an atherosclerotic middle cerebral artery associated with improvement in regional cerebral blood flow. AJNR Am J Neuroradiol 1990; 11: 878-80.

[10] Touho H, Ohnishi H, Karasawa J, Furuoka N, Komatsu T. Percutaneous transluminal angioplasty for acute stroke due to stenosis of major cerebral vessels: Report of two cases. Surg Neurol 1994; 41: 362-7.

[11] Takis C, Kwan ES, Pessin MS, Jacobs DH, Caplan LR. Intracranial angioplasty: Experience and complications. AJNR Am J Neuroradiol 1997; 18: 1661-8.

[12] Terada T, Tsuura M, Matsumoto H, et al. Endovascular therapy for stenosis of the petrous or cavernous portion of the internal carotid artery: Percutaneous transluminal angioplasty compared with stent placement. J Neurosurg 2003; 98: 491-7.

[13] Connors JJ 3rd, Wojak JC. Percutaneous transluminal angioplasty for intracranial atherosclerotic lesions: Evolution of technique and short-term results. J Neurosurg 1999; 91: 415-23.

[14] Gress DR, Smith WS, Dowd CF, Van Halbach V, Finley RJ, Higashida RT. Angioplasty for intracranial symptomatic vertebrobasilar ischemia. Neurosurgery 2002; 51: 23-7; Discussion 27-9.

[15] Wojak JC, Dunlap DC, Hargrave KR, DeAlvare LA, Culbertson $\mathrm{HS}$, Connors $\mathrm{JJ} 3^{\text {rd }}$. Intracranial angioplasty and stenting: Longterm results from a single center. AJNR Am J Neuroradiol 2006; 27: 1882-92.

[16] Marks MP, Wojak JC, Al-Ali F, et al. Angioplasty for symptomatic intracranial stenosis: Clinical outcome. Stroke 2006; 37: 1016-20.

[17] Marks MP, Marcellus M, Norbash AM, Steinberg GK, Tong D, Albers GW. Outcome of angioplasty for atherosclerotic intracranial stenosis. Stroke 1999; 30: 1065-9.

[18] Stoeckel D, Pelton A, Duerig T. Self-expanding nitinol stents: Material and design considerations. Eur Radiol 2004; 14: 292-301.

[19] Hoh DJ, Hoh BL, Amar AP, Wang MY. Shape memory alloys: Metallurgy, biocompatibility, and biomechanics for neurosurgical applications. Neurosurgery 2009; 64: 199-214; Discussion 214195.

[20] Stoeckel CB, Duda S. A survey of stent designs. Minim Invasive Ther Allied Technol 2002; 11: 137-47. 
[21] Feldman RL, Trigg L, Gaudier J, Galat J. Use of coronary palmazschatz stent in the percutaneous treatment of an intracranial carotid artery stenosis. Cathet Cardiovasc Diagn 1996; 38: 316-19.

[22] Gomez CR, Misra VK, Liu MW, et al. Elective stenting of symptomatic basilar artery stenosis. Stroke 2000; 31: 95-9.

[23] Rasmussen PA, Perl J 2 ${ }^{\text {nd }}$, Barr JD, et al. Stent-assisted angioplasty of intracranial vertebrobasilar atherosclerosis: An initial experience. J Neurosurg 2000; 92: 771-8.

[24] Stenting of symptomatic atherosclerotic lesions in the vertebral or intracranial arteries (ssylvia): Study results. Stroke 2004; 35: 138892.

[25] Bose A, Hartmann M, Henkes H, et al. A novel, self-expanding, nitinol stent in medically refractory intracranial atherosclerotic stenoses: The wingspan study. Stroke 2007; 38: 1531-7.

[26] Fiorella D, Levy EI, Turk AS, et al. US multicenter experience with the wingspan stent system for the treatment of intracranial atheromatous disease: Periprocedural results. Stroke 2007; 38: 8817.

[27] Zaidat OO, Klucznik R, Alexander MJ, et al. The nih registry on use of the wingspan stent for symptomatic $70-99 \%$ intracranial arterial stenosis. Neurology 2008; 70: 1518-24.

[28] Wolfe BF, Hussain SI, Lynch JR, Zaidat OO. Long term clinical and angiographic outcomes with the wingspan stent for treatment of symptomatic $50-99 \%$ intracranial atherosclerosis: Single center experience in 51 cases. J Neurointerv Surg 2009; 1: 40-3.

[29] Henkes H, Miloslavski E, Lowens S, Reinartz J, Liebig T, Kuhne D. Treatment of intracranial atherosclerotic stenoses with balloon dilatation and self-expanding stent deployment (wingspan). Neuroradiology 2005; 47: 222-8.

[30] Levy EI, Turk AS, Albuquerque FC, et al. Wingspan in-stent restenosis and thrombosis: Incidence, clinical presentation, and management. Neurosurgery 2007; 61: 644-50; Discussion 650-41.

[31] Jiang WJ, Wang YJ, Du B, et al. Stenting of symptomatic m1 stenosis of middle cerebral artery: An initial experience of 40 patients. Stroke 2004; 35: 1375-80.

[32] Mazighi M, Yadav JS, Abou-Chebl A. Durability of endovascular therapy for symptomatic intracranial atherosclerosis. Stroke 2008; 39: 1766-9.

[33] Gupta R, Al-Ali F, Thomas AJ, et al. Safety, feasibility, and shortterm follow-up of drug-eluting stent placement in the intracranial and extracranial circulation. Stroke 2006; 37: 2562-6.

[34] Morice MC, Serruys PW, Sousa JE, et al. A randomized comparison of a sirolimus-eluting stent with a standard stent for coronary revascularization. N Engl J Med 2002; 346: 1773-80.

[35] Abou-Chebl A, Bashir Q, Yadav JS. Drug-eluting stents for the treatment of intracranial atherosclerosis: Initial experience and midterm angiographic follow-up. Stroke 2005; 36: e165-8.

[36] Qureshi AI, Kirmani JF, Hussein HM, et al. Early and intermediate-term outcomes with drug-eluting stents in high-risk patients with symptomatic intracranial stenosis. Neurosurgery 2006; 59: 1044-51; Discussion 1051.

[37] Steinfort B, Ng PP, Faulder K, et al. Midterm outcomes of paclitaxel-eluting stents for the treatment of intracranial posterior circulation stenoses. J Neurosurg 2007; 106: 222-5.

[38] Virmani R, Guagliumi G, Farb A, et al. Localized hypersensitivity and late coronary thrombosis secondary to a sirolimus-eluting stent: Should we be cautious? Circulation 2004; 109: 701-5.

[39] Guagliumi G, Farb A, Musumeci G, et al. Images in cardiovascular medicine. Sirolimus-eluting stent implanted in human coronary artery for 16 months: Pathological findings. Circulation 2003; 107: $1340-41$

[40] Levy EI, Hanel RA, Howington JU, et al. Sirolimus-eluting stents in the canine cerebral vasculature: A prospective, randomized, blinded assessment of safety and vessel response. J Neurosurg 2004; 100: 688-94.

[41] Qureshi AI, Hussein HM, El-Gengaihy A, Abdelmoula M, Suri MFK. Concurrent comparison of outcomes of primary angioplasty and of stent placement in high-risk patients with symptomatic intracranial stenosis. Neurosurgery 2008; 62: 1053-60; Discussion 1060-52.

[42] Nahab F, Lynn MJ, Kasner SE, et al. Risk factors associated with major cerebrovascular complications after intracranial stenting. Neurology 2009; 72: 2014-9.

[43] Gupta R, Schumacher HC, Mangla S, et al. Urgent endovascular revascularization for symptomatic intracranial atherosclerotic stenosis. Neurology 2003; 61: 1729-35.
[44] Fiorella D, Chow MM, Anderson M, Woo H, Rasmussen PA, Masaryk TJ. A 7-year experience with balloon-mounted coronary stents for the treatment of symptomatic vertebrobasilar intracranial atheromatous disease. Neurosurgery 2007; 61: 236-42; Discussion 242-33.

[45] Jiang WJ, Du B, Leung TW, Xu XT, Jin M, Dong KH. Symptomatic intracranial stenosis: Cerebrovascular complications from elective stent placement. Radiology 2007; 243: 188-97.

[46] Jiang WJ, Srivastava T, Gao F, Du B, Dong KH, Xu XT. Perforator stroke after elective stenting of symptomatic intracranial stenosis. Neurology 2006; 66: 1868-72.

[47] Cruz-Flores S, Diamond AL. Angioplasty for intracranial artery stenosis. Cochrane Database Syst Rev 2006; 3: CD004133.

[48] Suh DC, Kim JK, Choi JW, et al. Intracranial stenting of severe symptomatic intracranial stenosis: Results of 100 consecutive patients. Am J Neuroradiol 2008; 29: 781-5.

[49] Gupta R. Symptomatic intracranial atherosclerotic disease: What is the best treatment option? Stroke 2008; 39: 1661-2.

[50] Weintraub WS. The pathophysiology and burden of restenosis. Am J Cardiol 2007; 100: 3K-9K.

[51] Wainwright CL, Miller AM, Wadsworth RM. Inflammation as a key event in the development of neointima following vascular balloon injury. Clin Exp Pharmacol Physiol 2001; 28: 891-95.

[52] Turk AS, Levy EI, Albuquerque FC, et al. Influence of patient age and stenosis location on wingspan in-stent restenosis. Am J Neuroradiol 2008; 29: 23-7.

[53] Groschel K, Schnaudigel S, Pilgram SM, Wasser K, Kastrup A. A systematic review on outcome after stenting for intracranial atherosclerosis. Stroke 2009; 40: e340-47.

[54] Mori T, Fukuoka M, Kazita K, Mori K. Follow-up study after intracranial percutaneous transluminal cerebral balloon angioplasty. AJNR Am J Neuroradiol 1998; 19: 1525-33.

[55] Schumacher HC, Meyers PM, Higashida RT, et al. Reporting standards for angioplasty and stent-assisted angioplasty for intracranial atherosclerosis. Stroke 2009; 40: e348-65.

[56] Gruntzig AR, Senning A, Siegenthaler WE. Nonoperative dilatation of coronary-artery stenosis: Percutaneous transluminal coronary angioplasty. N Engl J Med 1979; 301: 61-8.

[57] Kole M, Amin B, Marin H, Russman A, Sanders W. Intracranial angioplasty and stent placement for direct cerebral revascularization of nonacute intracranial occlusions and near occlusions. Neurosurg Focus 2009; 26: E3.

[58] Mehta SR, Yusuf S, Peters RJ, et al. Effects of pretreatment with clopidogrel and aspirin followed by long-term therapy in patients undergoing percutaneous coronary intervention: The pci-cure study. Lancet 2001; 358: 527-33.

[59] Smith SC Jr, Feldman TE, Hirshfeld JW Jr, et al. Acc/aha/scai 2005 guideline update for percutaneous coronary intervention-summary article: A report of the american college of cardiology/american heart association task force on practice guidelines (acc/aha/scai writing committee to update the 2001 guidelines for percutaneous coronary intervention). Circulation 2006; 113: 156-75

[60] Reavey-Cantwell JF, Fox WC, Reichwage BD, et al. Factors associated with aspirin resistance in patients premedicated with aspirin and clopidogrel for endovascular neurosurgery. Neurosurgery 2009; 64: 890-895; Discussion 895-96.

[61] Prabhakaran S, Wells KR, Lee VH, Flaherty CA, Lopes DK. Prevalence and risk factors for aspirin and clopidogrel resistance in cerebrovascular stenting. Am J Neuroradiol 2008; 29: 281-5.

[62] Pandya D, Fitzsimmons B, Wolfe T, et al. Measurement of antiplatelet inhibition during neurointerventional procedures: The effect of antithrombotic duration and loading dose. J Neuroimaging 2010; 20(1): 64-9.

[63] Samuels OB, Joseph GJ, Lynn MJ, Smith HA, Chimowitz MI. A standardized method for measuring intracranial arterial stenosis. Am J Neuroradiol 2000; 21: 643-6.

[64] Dawkins AA, Evans AL, Wattam J, et al. Complications of cerebral angiography: A prospective analysis of 2,924 consecutive procedures. Neuroradiology 2007; 49: 753-9.

[65] Hahnel S, Trossbach M, Braun C, et al. Small-vessel stents for intracranial angioplasty: in vitro comparison of different stent designs and sizes by using ct angiography. AJNR Am J Neuroradiol 2003; 24: 1512-16.

[66] Trossbach M, Hartmann M, Braun C, Sartor K, Hahnel S. Small vessel stents for intracranial angioplasty: in vitro evaluation of in- 
stent stenoses using ct angiography. Neuroradiology 2004; 46: 459463.

[67] Buhk JH, Lingor P, Knauth M. Angiographic ct with intravenous administration of contrast medium is a noninvasive option for follow-up after intracranial stenting. Neuroradiology 2008; 50: 349-54.

[68] Nehra A, Moran CJ, Cross DT 3rd, Derdeyn CP. Mr safety and imaging of neuroform stents at 3t. Am J Neuroradiol 2004; 25: $1476-8$.

[69] Lovblad KO, Yilmaz H, Chouiter A, et al. Intracranial aneurysm stenting: Follow-up with $\mathrm{mr}$ angiography. J Magn Reson Imaging 2006; 24: 418-22.

[70] Brisman JL. Wingspan stenting of symptomatic extracranial vertebral artery stenosis and perioperative evaluation using quantitative magnetic resonance angiography: Report of two cases. Neurosurg Focus 2008; 24: E14.

[71] Prabhakaran S, Warrior L, Wells KR, Jhaveri MD, Chen M, Lopes DK. The utility of quantitative magnetic resonance angiography in the assessment of intracranial in-stent stenosis. Stroke 2009; 40: 991-93.
[72] Meyers PM, Schumacher HC, Tanji K, Higashida RT, Caplan LR. Use of stents to treat intracranial cerebrovascular disease. Annu Rev Med 2007; 58: 107-22.

[73] Berkefeld J, Zanella FE. Intracranial stenting of atherosclerotic stenoses: Current status and perspectives. Klin Neuroradiol 2009; 19: 38-44.

[74] Chimowitz MI. Stenting vs aggressive medical management for preventing recurrent stroke in intracranial stenosis (Sammpris), 2009.

[75] Meyers PM, Schumacher HC, Higashida RT, et al. Indications for the performance of intracranial endovascular neurointerventional procedures: A scientific statement from the american heart association council on cardiovascular radiology and intervention, stroke council, council on cardiovascular surgery and anesthesia, interdisciplinary council on peripheral vascular disease, and interdisciplinary council on quality of care and outcomes research. Circulation 2009; 119: 2235-49.

[76] Samaniego EA, Hetzel S, Thirunarayanan S, Aagaard-Kienitz B, Turk AS, Levine R. Outcome of symptomatic intracranial atherosclerotic disease. Stroke 2009; 40: 2983-7.

(C) Lazzaro and Chen; Licensee Bentham Open.

This is an open access article licensed under the terms of the Creative Commons Attribution Non-Commercial License (http://creativecommons.org/licenses/by$\mathrm{nc} / 3.0 /$ ) which permits unrestricted, non-commercial use, distribution and reproduction in any medium, provided the work is properly cited. 